\title{
In vitro Antifungal Activity of Psidium Guajava Based Silver Nanoparticles
}

\author{
Sheik Shehensha ${ }^{1 *}$ (D) and Jyothi M. Vijaya² \\ ${ }^{1}$ Jawaharlal Nehru Technological University Anantapur, Anantapuramu, Pharmaceutical Sciences. Andhra \\ Pradesh - 515 721, India. \\ ${ }^{2}$ Raghavendra Institute of Pharmaceutical Education and Research, Anantapuramu, Andra Pradesh - 515721 , \\ India.
}

\begin{abstract}
To prepare and characterize silver nanoparticles from Guava leaves (Psidium guajava), extracts (chloroform and ethanol). The fabricated silver nanoparticles were tested on resistant fungal strains, Aspergillus niger and Candida glabrata. Psidium guajava leaf extracts were obtained by cold maceration method, by using Chloroform and Ethanol. To one $\mathrm{mL}$ of extract $2 \mathrm{mM}$ silver nitrate solution was added. The mixture was kept overnight in a dark chamber at room temperature. The solution was centrifuged at $10,000 \mathrm{rpm}$ for 15 minutes and filtered by wattman filter paper after centrifugation. Psidium guajava leaf extract based silver nanoparticles were prepared and evaluated for anti-fungal activity by microtitre well plate method on resistant strains Aspergillus niger and Candida glabrata. The silver nanoparticles showed significant activity at $120 \mu \mathrm{L}$, Nystatin was used as standard.
\end{abstract}

Keywords: Psidium guajava, Silver nanoparticles, Zeta potential, SEM analysis, Resistant strains, Antifungal activity

\footnotetext{
*Correspondence: shahenshah7@gmail.com; 08554-255646
}

(Received: March 18, 2020; accepted: August 10, 2020)

Abbreviations: GES- Psidium guajava Ethanol Silver nanoparticles, GCS- Psidium guajava Chloroform Silver nanoparticles, Fr-C.g: Fluconazole resistant Candida glabrata, Flu: Fluconazole, Vr-A.f: Voriconazole resistant Aspergillus niger.

Citation: Shehensha S, Vijaya JM. In vitro Antifungal Activity of Psidium Guajava Based Silver Nanoparticles. J Pure App/Microbiol. 2020;14(3):2075-2083. doi: 10.22207/JPAM.14.3.48

(c) The Author(s) 2020. Open Access. This article is distributed under the terms of the Creative Commons Attribution 4.0 International License which permits unrestricted use, sharing, distribution, and reproduction in any medium, provided you give appropriate credit to the original author(s) and the source, provide a link to the Creative Commons license, and indicate if changes were made. 


\section{INTRODUCTION}

The preparation of silver nanoparticles (AgNPs) employing plant extracts is an evolving field since phytochemicals acts as reducing and capping agents and are free from harmful chemicals. Silver possess bactericidal activity. The present research work focused on fabrication of silver nanoparticles (AgNPs) by Guava (Psidium guajava) leaf extracts from green chemistry view and to assess the antifungal potency of fabricated AgNPs on resistant fungal strains

Candida species are harmful to humans and cause superficial as well as innate mycoses in humans and are distributed worldwide. Candida albicans and glabrata are prevalent fungi which cause Candidiasis. It is an opportunistic pathogen. It causes infections of urinogenital tract and Candidaemia, mostly seen in less immune patients ${ }^{3}$. It is highly resistant to antifungal agents. The opportunistic fungi are found in normal body flora and become pathogenic and intrusive in less immune individuals. Inspite of improvements in antifungal remedy, the last two to three decades have perceived major contaminations involving Candida albicans, Candida glabrata. Aspergillus niger produces mycotoxins which affects liver and kidney ${ }^{4}$. Aspergillus niger is a pathogenic allergen commonly linked with respiratory infections in individuals with frail immune system. Therefore, new compounds should be researched as an alternative to combat such resistance. Azole resistance is reported in many Aspergillus species ${ }^{5}$. In immunocompromised individuals the infections due to bacteria and fungi may occur concurrently. The management for such infections is inadequate as anti-fungal agents show adverse effects, so the AgNPs may be an alternative antimicrobial agent.

\section{METHODS}

\section{Collection and authentication of plant part}

Psidium guajava leaves were collected

from medicinal garden in RIPER College, Ananthapuramu, India, authenticated with voucher no. 1834. The leaves were shade dried at room temperature for 14 days and blended into powder. The powder was kept in air tight container for further use.

Microorganism and culture conditions

Voriconazole resistant Aspergillus niger M046 (Clinical Isolate) and Fluconazole resistant Candida glabrata (ATCC200918) strains were used for present study. The organisms were maintained, grown, and sub cultured at $37^{\circ} \mathrm{C}$ on Peptone, Dextrose and Yeast extract. (PDA) plates $48 \mathrm{~h}$ prior to use in Biosafety level 1 laboratory.

\section{Preparation of plant material}

The powdered material was macerated in $200 \mathrm{~mL}$ of chloroform and ethanol, for four days with occasional stirring. The extract was filtered by using whatmann filter paper and dried under vacuum using rota-evaporator. The extracts were refrigerated and used further.

\section{Chemicals and reagents}

Silver nitrate $\left(\mathrm{AgNO}_{3}\right)$ was bought from Sigma Aldrich. The other reagents and chemicals used were of analytical quality and procured from Sigma Aldrich, India. During the experiment double distilled water was used.

Phytochemical screening of plant extracts

Phytochemical screening of Psidium guajava leaf extracts of ethanol and chloroform was performed to investigate the phytochemicals present ${ }^{6,7}$.

\section{Thin Layer Chromatographic (TLC) studies}

The $R_{f}$ values were found by one dimensional TLC using silica gel Gas immobile phase. The mobile phase used was $n$-hexane and ethyl acetate in ratio 7:3.

\section{Biosynthesis of Silver nanoparticles (Ag NPs)}

One $\mathrm{ml}$ of leaf extracts (chloroform and ethanol) was mixed with $10 \mathrm{ml}$ of $2 \mathrm{mM} \mathrm{AgNO}_{3}$ solution, in a $50 \mathrm{ml}$ beaker. The preparation was kept in dark, overnight at room temperature. The change of chloroform light yellow to brown determines formation of AgNPs. The obtained nanoparticles were parted by centrifugation at 10000 rpm for 15 minutes $^{8}$. The solution was filtered after centrifugation process by whatmann filter paper and kept in refrigerator for future use.

\section{Characterization of nanoparticles}

To characterise the AgNPs absorption studies were carried out on a UV-visible spectrophotometer ${ }^{9}$ (LAB INDIA, UV-3092) for well-dispersed extract nanoparticles solution in between the wavelength range of $200-800 \mathrm{~nm}$. The Size distribution of the prepared nanoparticles and zeta potential was determined by Zetasizer (Horiba SZ-100). The detailed morphology of nanoparticles was established by Scanning electron microscopic (SEM) images. 


\section{UV-Visible spectroscopy}

Reduction of silver nanoparticles during exposure to seed extract could be detected by the color change. A color change from light yellow to brown was observed when the seed extracts containing silver nitrate solution was kept for overnight. It may be due to reducing and capping ability of phytoconstituents of seed extract with aqueous $\mathrm{AgNO}_{3}$ solution. The $\mathrm{Ag}+$ ions were reduced to $\mathrm{Ag}^{\circ}$.

\section{Particle size and Zeta potential}

The size dispersal and poly-disperse property of the AgNPs in a suspension is determined by $\mathrm{DLS}^{10}$. The size and Zeta potential of the synthesised nanoparticles was determined by using Zetasizer (Horiba SZ-100 Ver 2.20). The size distribution of the AgNPs was measured by dynamic light scattering. Zeta potential values of nanoparticles in the range $+30 \mathrm{mV}$ or below -30 $\mathrm{mV}$ are considered electrostatically stable. The stabilization of nanoparticles is due to electrostatic interactions and steric hindrance provided by biomolecules.

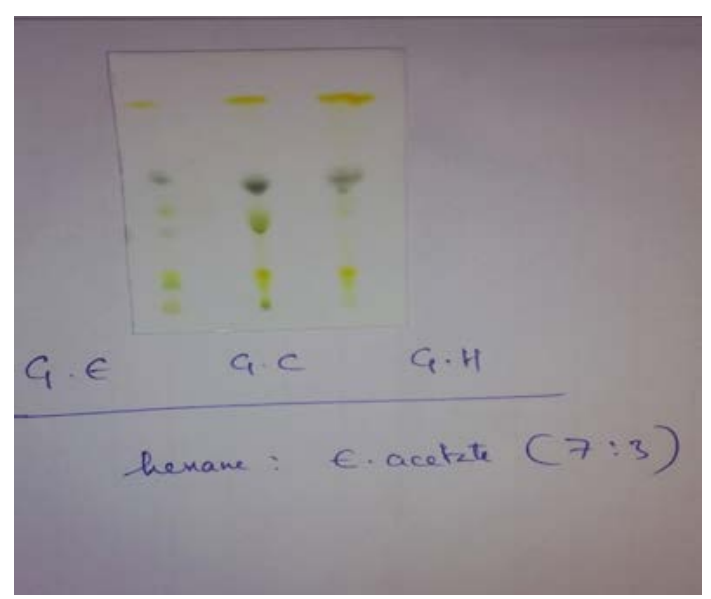

Fig. 1. TLC profile of the ethanol and chloroform extract of $P$. guajava leaf. Solvent system: Hexane : Ethyl acetate (7: 3).

\section{RESULTS}

Phytochemical Investigation

Phytochemical screening of the leaf extracts of Psidium guajava showed presence of phenols, tannins, terpenoids, flavonoids and glycosides as presented in (Table 1 )

\section{Thin Layer Chromatographic (TLC) studies}

The $R_{f}$ values obtained from ethanol $0.10,0.14,0.35,0.45,0.60,0.91$; and chloroform $0.14,0.37,0.58,0.89$ serve as characteristic fingerprint of Psidium guajava leaf. This data would therefore be suitable for monitoring the identity and purity of the plant material as depicted in Fig. 1.

\section{UV-Visible spectroscopy}

The fabricated silver nanoparticles revealed superior plasmon resonance absorbance at $432 \mathrm{~nm}$, as shown in (Fig. 2).

Particle size and Zeta potential

The AgNPs prepared from Nigella sativa chloroform extract, DLS analysis showed nanoparticles with an average diameter of $158 \mathrm{~nm}$, with a Polydispersity Index (PdI) of 0.309 for guava AgNPs (ethanol extract). The mean diameter 190

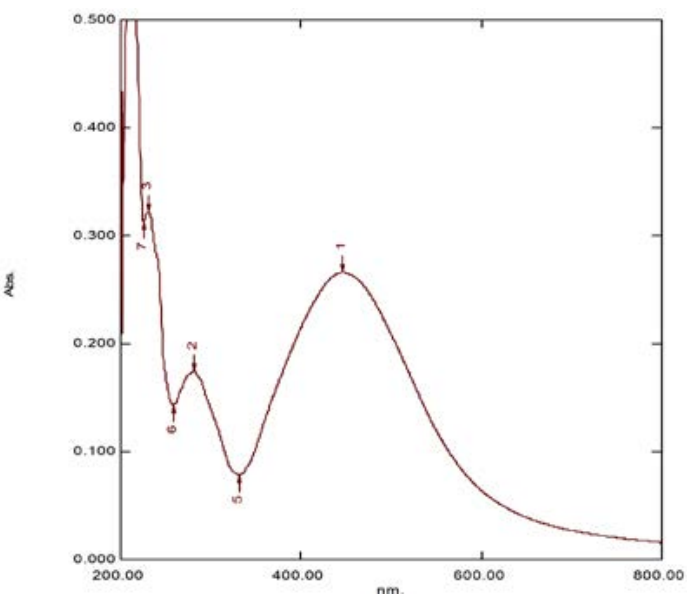

Fig. 2. UV -Visible spectra of Psidium guajava silver nanoparticles

Table 1. + indicates presence of constituent (positive), - indicates absence of constituent (negative).

\begin{tabular}{lccccc}
\hline Extracts & Phenols & Tannins & Terpenoids & Flavonoids & Glycosides \\
\hline Ethanol & + & + & + & + & + \\
Chloroform & + & + & + & + & + \\
\hline Journal of Pure and Applied Microbiology & & 2077 & & www.microbiologyjournal.org
\end{tabular}


$\mathrm{nm}$ with a Polydispersity Index of 0.321 for guava AgNPs (chloroform extract) as shown in (Table 1) and (Fig. 5). The zeta potential for AgNPs prepared from Psidium guajava chloroform extract was -18.8 $\mathrm{mV}$. In the case of AgNPs prepared from Psidium guajava ethanol extract, the zeta potential was $-8.9 \mathrm{mv}$ as shown in (Fig. 6).

\section{SEM analysis}

It confirms morphology and size particulars of AgNPs. The experimental result showed that the diameter of the prepared nanoparticle (chloroform extract) with average size of $158 \mathrm{~nm}$ as shown (Fig.-7).

\section{In vitro antifungal activity}

Minimum inhibitory and fungicidal concentrations (MIC/MFC)

The MIC is the least concentration of AgNPs which cause $90 \%$ decline in absorbance paralleled to control. MIC90 was measured in triad by broth micro-dilution method ${ }^{19}$ employing UV spectrophotometer. To determine MFC, aliquots were taken from each visually unblemished test tube after 48 hours incubation and positioned on newly prepared Yeast Extract Peptone Dextrose agar plates ${ }^{11}$. The plate entirely empty of any colony at last dilution gives Minimum Fungicidal Concentration value.

\section{Voriconazole Vs $V r$ - A.f}

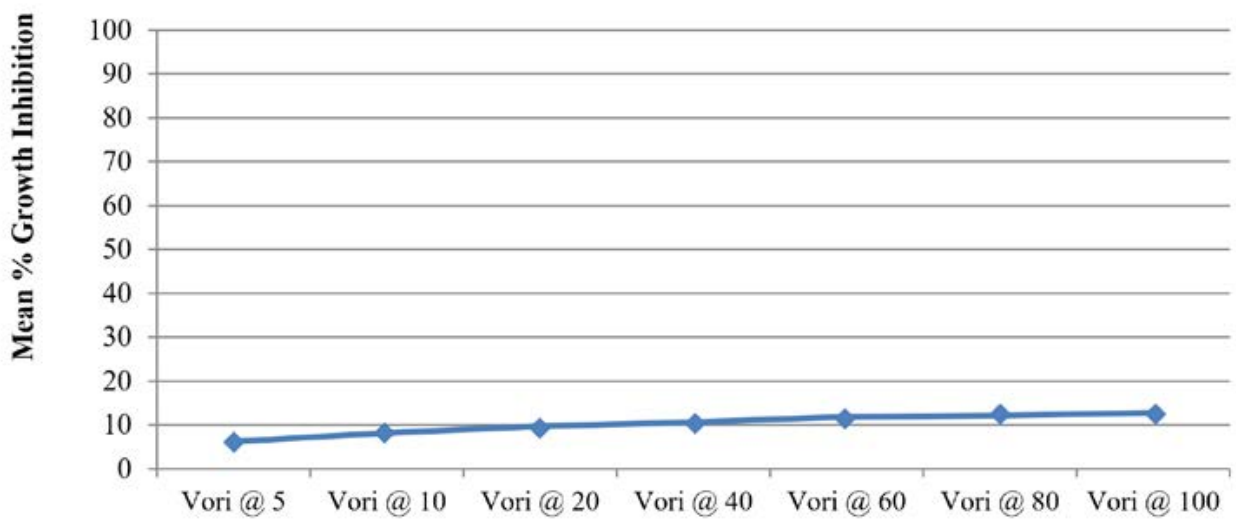

Fig. 3. Minimum percentage Growth Inhibition of Voriconazole resistant Aspergillus niger

\section{Fluconazole Vs Fr-C.g}

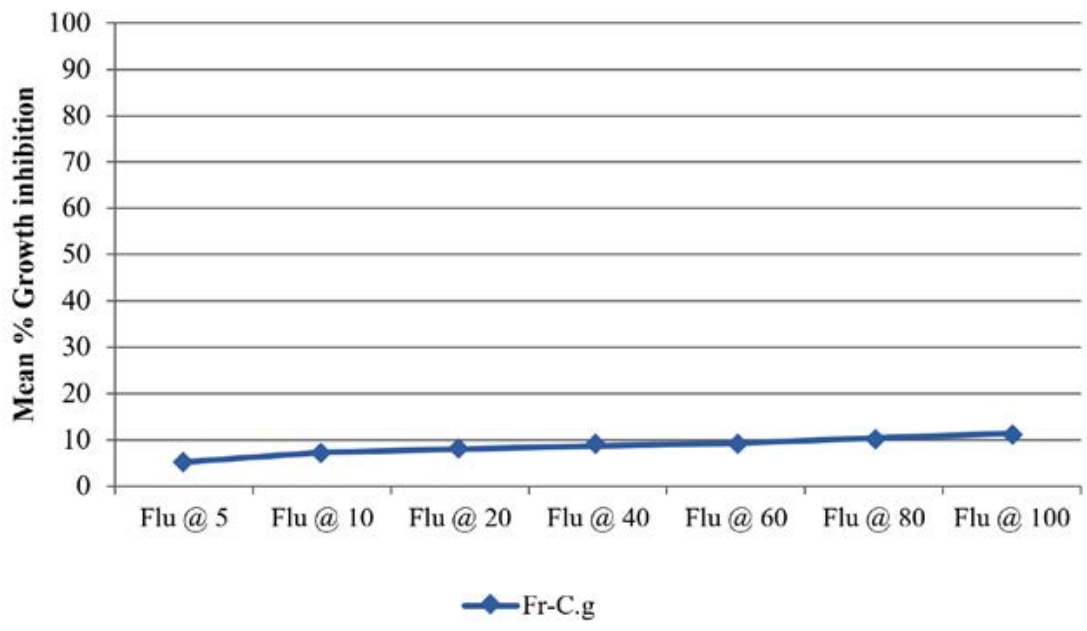

Fig. 4. Minimum percentage Growth Inhibition of Fluconazole resistant Candida glabrata 


\section{Antifungal activity}

Solutions of each compound (GE, GC, GES and GCS) were used at appropriate concentrations. Each Source solution (GE, GC,) was diluted to attain the final concentrations of $12.5,25$ and 50 $\mathrm{mg} / \mathrm{mL}$. Each formulation (GES, GCS) was diluted to obtain the final concentrations - 10, 20, 40,

Table 2. Zeta size and Zeta potential of Psidium guajava silver nanoparticles with Ethanol and Chloroform extract

\begin{tabular}{lccc}
\hline S. No & Sample & $\begin{array}{c}\text { Zeta size } \\
(\mathrm{nm})\end{array}$ & $\begin{array}{c}\text { Zeta potential } \\
(\mathrm{mv})\end{array}$ \\
\hline 1. & GES & 158 & -8.9 \\
2. & GCS & 195 & -18.8 \\
\hline
\end{tabular}

60, 80, 100 and $120 \mu \mathrm{g} / \mathrm{mL}$. Two fungal resistant strains namely Voriconazole resistant Aspergillus niger and Fluconazole resistant Candida glabrata were cultured as per standard protocol. An aliquot of $80 \mu \mathrm{l}$ of every dilution of compounds were poured on a 96-welled $(12 \times 8)$ microtitre plate, laterally with $100 \mu \mathrm{l}$ of fungal broth, $20-\mu \mathrm{l}$ of fungal inoculum and a $5-\mu \mathrm{l}$ aliquot of $0.5 \%$ of 2,3,5-trifenyl tetrazolium chloride (TTC). All the above were poured on to a well and incubated at $37^{\circ} \mathrm{C}$ for $24 \mathrm{hrs}$ in Orbital shaker. The appearance of pink color is owed to TTC which indicates fungal growth, and the absence of color represents mean inhibition of fungal growth. The first well of microplate is control without any additional molecules. And second well contains Nystatin as

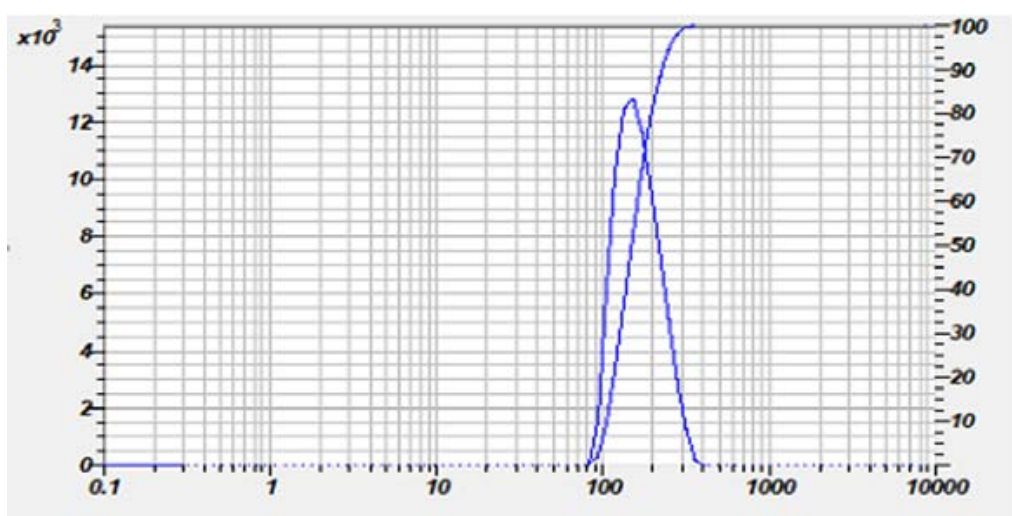

A

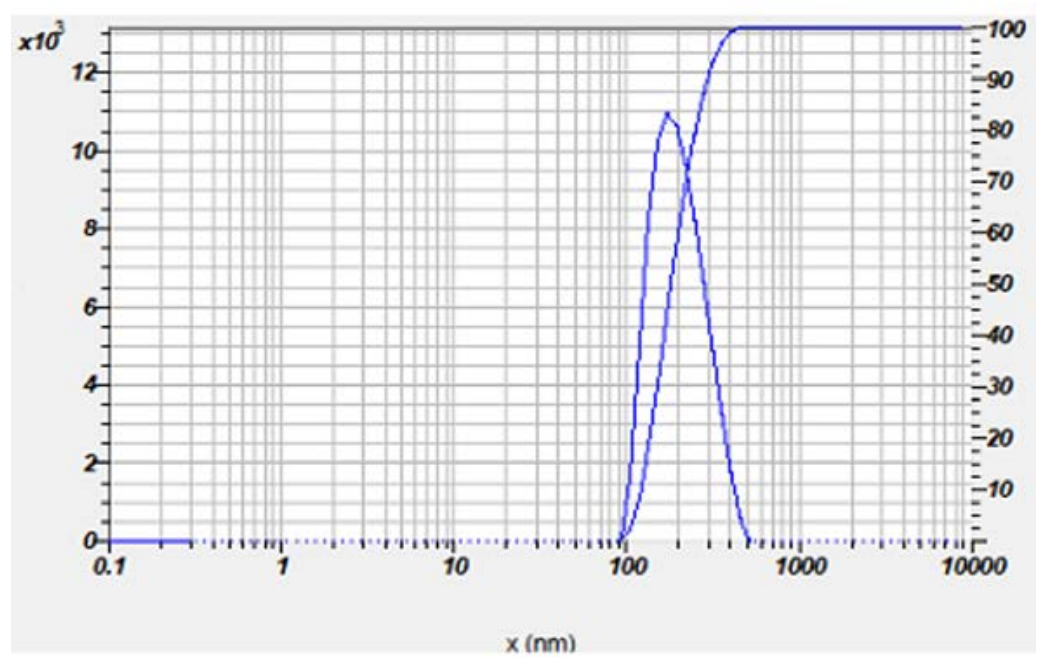

B

Fig. 5. Size distribution of Nigella sativa silver nanoparticles (A) Ethanolic extract (B) Chloroform extract 
Table 3. Validation of resistant fungal strains: The resistant fungal strain, Aspergillus niger and Candida glabrata was validated by using Voriconazole (vori) and Fluconazole (Flu) respectively. The mean percentage growth inhibition of fungi was measured at 5, 10, 20, $40,60,80$ and $100 \mu \mathrm{g} / \mathrm{ml}$

\begin{tabular}{lcc}
\hline $\begin{array}{l}\text { Drug \& Conc. in } \\
\mu \text { g per mL }\end{array}$ & $\begin{array}{c}\text { Mean \% growth } \\
\text { inhibition of } \\
\text { Vr-A.f }(\mathrm{n}=3)\end{array}$ & SD \\
\hline Vori @ 5 & 6.23 & 1.52 \\
Vori @ 10 & 8.21 & 1.69 \\
Vori @ 20 & 9.68 & 1.74 \\
Vori @ 40 & 10.69 & 1.28 \\
Vori @ 60 & 11.85 & 0.87 \\
Vori @ 80 & 12.17 & 1.35 \\
Vori @ 100 & 12.84 & 0.95 \\
\hline
\end{tabular}

positive control. The MIC value was measured at the well, where no color was established. $90 \%$ of growth inhibition was considered as MIC of the compound as per standard protocol ${ }^{12}$.

\section{DISCUSSION}

Candida glabrata is next to Candida albicans in causing candidiasis. These fungi show resistance to antifungal agents. C. glabrata is linked with high death rates in immune-compromised patients. Azole resistance is reported in many Aspergillus species. Contemporary antifungal drugs are not effective and there is an imperative necessity for novel anti-fungal drugs. The present work aims to synthesize silver nanoparticles by using leaf extracts of Psidium guajava with $2 \mathrm{mM} \mathrm{AgNo}$ solution. The guava leaf extract

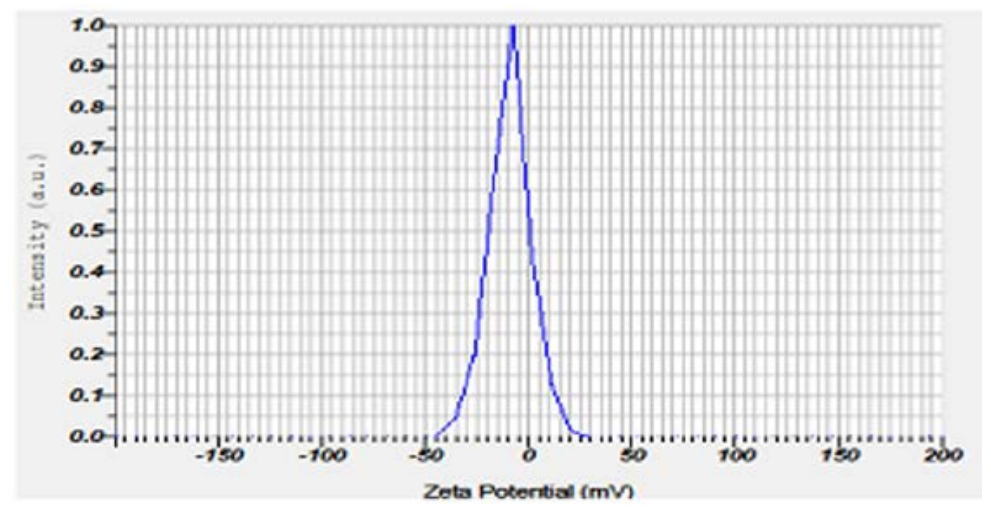

A

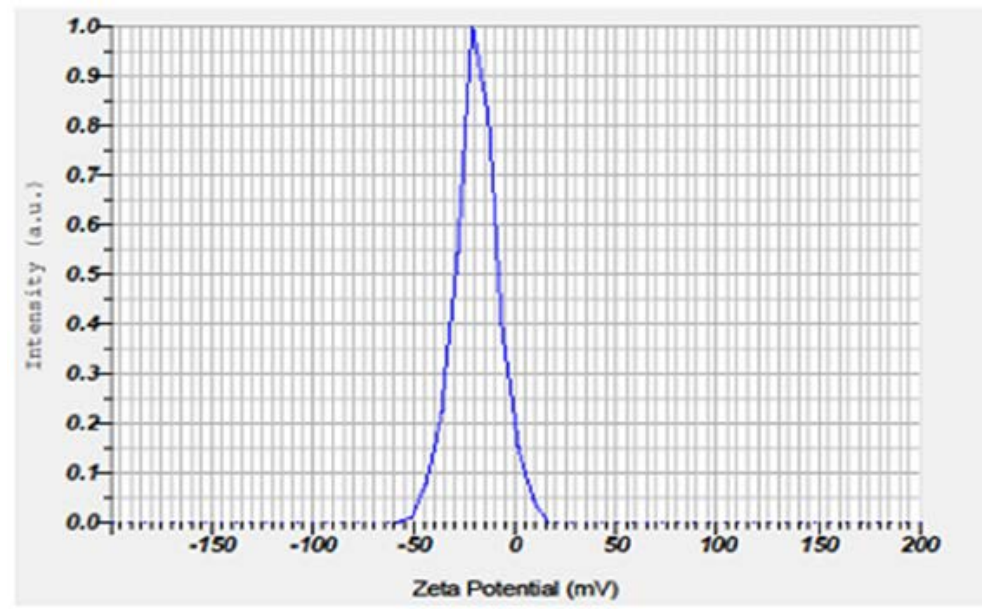

B

Fig. 6. Zeta Potential of Psidium guajava silver nanoparticles (A) Ethanolic extract (B) Chloroform extract 


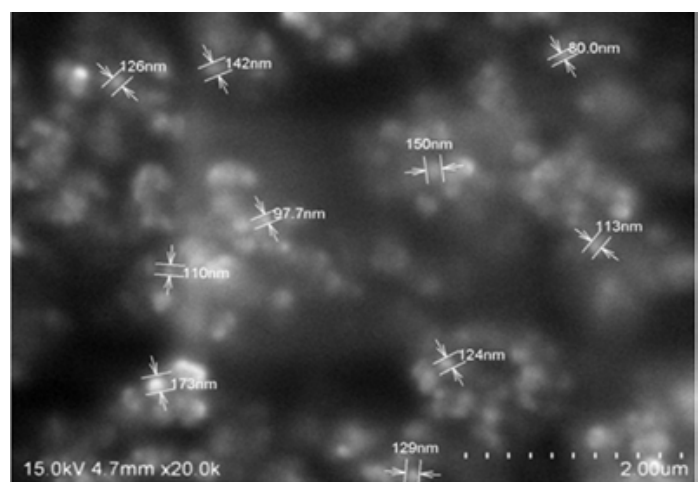

Fig. 7. SEM image of Psidium guajava- Chloroform silver nanoparticles (ethanol) showed presence of phenols, terpenoids, glycosides and flavonoids. The chloroform leaf extract showed all the above constituents along with saponins. The $R_{f}$ values from TLC suggests presence of flavonoids, terpenoids and glycosides. The color of the solution changes and gives surface plasmon resonance at $432 \mathrm{~nm}$ as presented in Fig.1. The particle size and zeta potential was found to be $158 \mathrm{~nm}, 195 \mathrm{~nm}$ and -8.9 and -18.8.The morphology of fabricated AgNPs was confirmed by SEM. The antifungal efficacy of AgNPs synthesized using plant extracts was evaluated against resistant Aspergillus niger and Candida glabrata, the strains were validated using Voriconazole and

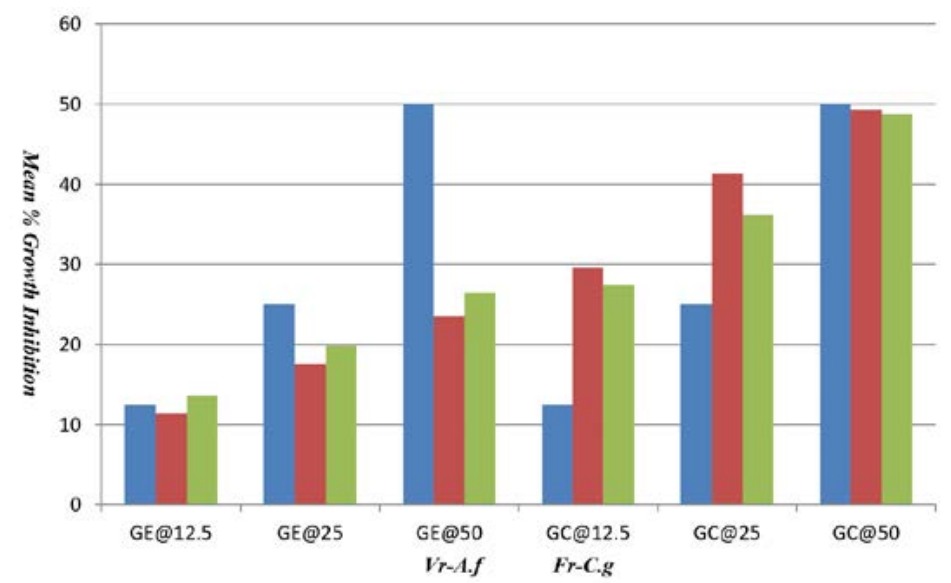

Fig. 8. Mean percentage growth inhibition of Psidium guajava leaf extract (ethanol and chloroform) against Aspergillus niger and Candida glabrata

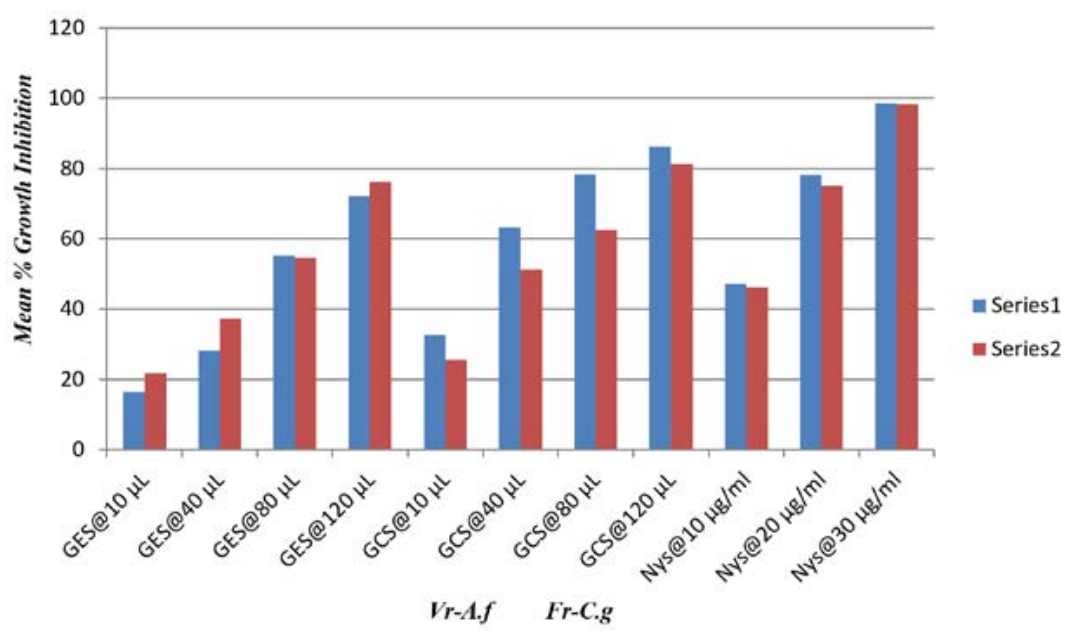

Fig. 9. Mean percentage growth inhibition of synthesized AgNPs (GES and GEC) against Aspergillus niger and Candida glabrata 
Table 4. Fluconazole resistant Candida glabrata

\begin{tabular}{lcc}
\hline $\begin{array}{l}\text { Drug \& Conc. in } \\
\mu g \text { per } \mathrm{mL}\end{array}$ & $\begin{array}{c}\text { Mean \% growth } \\
\text { inhibition of } \\
\text { Fr-C.g }(\mathrm{n}=3)\end{array}$ & SD \\
\hline Flu @ 5 & 5.22 & 1.23 \\
Flu @ 10 & 7.31 & 1.68 \\
Flu @ 20 & 8.03 & 1.46 \\
Flu @ 40 & 8.76 & 1.09 \\
Flu @ 60 & 9.36 & 0.84 \\
Flu @ 80 & 10.45 & 0.63 \\
Flu @ 100 & 11.38 & 0.72 \\
\hline
\end{tabular}

Table 5. Anti-fungal activity of Guava leaf extracts ( GEGuava leaf Ethanol extract, GC- Guava leaf Chloroform extract)

\begin{tabular}{lcc}
\hline $\begin{array}{l}\text { Conc. in } \\
\mathrm{mg} / \mathrm{mL}\end{array}$ & $\begin{array}{c}\text { Vr-A.f } \\
\text { Mean \% growth } \\
\text { inhibition of } \\
\text { Vr-A.f }\end{array}$ & $\begin{array}{c}\text { Fr-C.g } \\
\text { Mean \% growth } \\
\text { inhibition of } \\
\text { Fr-C.g }\end{array}$ \\
\hline GE @ 12.5 & 11.43 & 13.67 \\
GE @ 25 & 17.55 & 19.82 \\
GE @ 50 & 23.56 & 26.49 \\
GC @ 12.5 & 29.58 & 27.39 \\
GC @ 25 & 41.33 & 36.21 \\
GC @ 50 & 49.23 & 48.75
\end{tabular}

Fluconazole respectively. The guava leaf extracts showed minimal antifungal activity compared to AgNPs. The MIC value of synthesized nanoparticles against Aspergillus niger and C. albicans was 120 $\mu \mathrm{L}$, shown in (Fig. 8) and (Fig. 9). Nystatin was used as standard drug.

The fungal organisms to be tested here have the potential to cause infections in humans, particularly immunosuppressed individuals. Thus, adequate biosafety practices need to be followed. For Aspergillus spp., all manipulations should be performed within a biological safety cabinet to prevent contamination of other laboratory surfaces.The antifungal property of AgNPs on the resistant Candida glabrata and Aspergillus niger, may be owed to disturbance of membrane structure which damages fungal cells. The phytoconstituents of Psidium guajava leaf have the ability to constrain the pathogens. Henceforth biologically fabricated AgNPs, alike the one used
Table 6. Antifungal activity of Silver nanoparticles synthesised from guava leaf ethanol and Chloroform extracts. (GES- Guava Leaf Ethanol extract silver Nanoparticles, GCS- Guava Leaf Chloroform extract silver Nanoparticle

\begin{tabular}{|c|c|c|}
\hline $\begin{array}{l}\text { Volume spiked } \\
\text { in } \mu \mathrm{L}\end{array}$ & $\begin{array}{c}\text { Mean \% growth } \\
\text { inhibition of } \\
\text { Vr-A.f }\end{array}$ & $\begin{array}{c}\text { Mean \% growth } \\
\text { inhibition of } \\
\text { Fr-C.g }\end{array}$ \\
\hline GES @ 10 & 16.52 & 21.88 \\
\hline 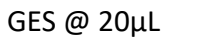 & 28.14 & 29.87 \\
\hline GES @ 40 & 42.36 & 37.27 \\
\hline GES @ 60 & 49.46 & 45.52 \\
\hline GES @ 80 & 55.27 & 54.63 \\
\hline GES @ 100 & 64.23 & 71.23 \\
\hline GES@ @ 120 & 72.12 & 76.23 \\
\hline GCS @ $10 \mu \mathrm{L}$ & 32.65 & 25.63 \\
\hline GCS @ 20 & 49.72 & 38.27 \\
\hline GCS@ @ 40 & 63.32 & 51.32 \\
\hline GCS@ @ 60 & 71.19 & 58.47 \\
\hline GCS @ 80 & 78.35 & 62.63 \\
\hline GCS @ 100 & 82.18 & 71.56 \\
\hline GCS @ 120 & 86.33 & 81.34 \\
\hline Nys @ $5 \mu \mathrm{g} / \mathrm{ml}$ & 32.56 & 34.96 \\
\hline Nys @ $10 \mu \mathrm{g} / \mathrm{ml}$ & 47.23 & 46.22 \\
\hline Nys @ 15 g/ml & 63.28 & 61.39 \\
\hline Nys @ $20 \mu \mathrm{g} / \mathrm{ml}$ & 78.25 & 75.14 \\
\hline Nys @ $25 \mu \mathrm{g} / \mathrm{ml}$ & 92.35 & 89.36 \\
\hline Nys @ $30 \mu \mathrm{g} / \mathrm{ml}$ & 98.56 & 98.36 \\
\hline Nys @ 35 g/ml & 99.68 & 99.12 \\
\hline
\end{tabular}

in the current study, can be considered as potent antifungal agents.

\section{CONCLUSION}

The AgNPs synthesized from Psidium guajava leaf extracts exhibited significant fungicidal activity against resistant strains like Aspergillus niger and Candida glabrata. The resistant fungi were validated by Voriconazole and Fluconazole. The synthesised AgNPs showed better anti-fungal activity than leaf extracts, the increased action is due to presence of Silver ions. The cell morphology is targeted to a great degree representing that these bio-fabricated AgNPs disrupts the integrity of fungal cells, making it friable, which leads to permeable and leaky fungal cells and eventually leads to death. The current work culminates the antifungal ability and method of action of phytogenically synthesized AgNPs. Future exploration on animal models will help to 
explore the invivo efficiency of these antifungal agents.

\section{ACKNOWLEDGMENTS}

We would like to express our heartfelt thanks to Principal YPR, Vice-Principal JRR and $R \& D$ Director $P R$ of Raghavendra Institute of Pharmaceutical Education and Research for providing the necessary facilities.

\section{CONFLICT OF INTEREST}

The authors declare that there is no conflict of interest.

\section{AUTHORS' CONTRIBUTION}

All authors listed have made a substantial, direct and intellectual contribution to the work, and approved it for publication.

\section{FUNDING}

None.

\section{ETHICS STATEMENT}

This article does not contain any studies with human participants or animals performed by any of the authors.

\section{DATA AVAILABILITY}

All datasets generated or analysed during this study are included in the manuscript and/or the Supplementary Files.

\section{REFERENCE}

1. Shekhawat MS, Manokari M, Kannan N, Revathi J, Latha R. Synthesis of silver nanoparticles using Cardiospermum halicacabum L. leaf extract and their characterization. J Phytopharmacol. 2013;2(5):15-20.

2. Bose D, Chatterjee S. Biogenic synthesis of silver nanoparticles using guava (Psidium guajava) leaf extract and its antibacterial activity against Pseudomonas aeruginosa. Applied Nanoscience. 2016;6(6):895-901. doi: 10.1007/s13204-015-0496-5

3. Khatoon N, Sharma Y, Sardar M, Manzoor N. Mode of action and anti-Candida activity of Artemisia annua mediated-synthesized silver nanoparticles. J Mycol Med. 2019;29(3):201-219. doi: 10.1016/j. mycmed.2019.07.005

4. Gautam AK, Sharma S, Avasthi S, Bhadauria R. Diversity, pathogenicity and toxicology of A. niger: an important spoilage fungi. Research Journal of Microbiology. 2011;6(3):270-280. doi: 10.3923/jm.2011.270.280

5. Howard SJ, Harrison E, Bowyer P, Varga J, Denning DW. Cryptic species and azole resistance in the Aspergillus niger complex. Antimicrob Agents Chemother. 2011;55(10):4802-4809. doi: 10.1128/AAC.00304-11

6. Naseer S, Hussain S, Naeem N, Pervaiz M, Rahman M. The phytochemistry and medicinal value of Psidium guajava (guava). Clinical Phytoscience. 2018;4(1):1-8. doi: 10.1186/s40816-018-0093-8

7. Gayathri V, Kiruba D. Preliminary Phytochemical Analysis of Leaf Powder Extracts of Psidium guajava L. International Journal of Pharmacognosy and Phytochemical Research. 2014;6(2):332-334.

8. Tripathi A, Chandrasekaran N, Raichur AM, Mukherjee A. Antibacterial applications of silver nanoparticles synthesized by aqueous extract of Azadirachta indica (Neem) leaves. J Biomed Nanotechnol. 2009;5(1):9398. doi: 10.1166/jbn.2009.038

9. Mourdikoudis S, Pallares RM, Thanh NT. Characterization techniques for nanoparticles: comparison and complementarity upon studying nanoparticle properties. Nanoscale. 2018;10:1287112934.doi: 10.1039/C8NR02278J

10. Shekhawat MS, Manokari M, Kannan N, Revathi J, Latha R. Synthesis of silver nanoparticles using Cardiospermum halicacabum L. leaf extract and their characterization. J Phytopharmacol. 2013;2(5):15-20.

11. Pierce CG, Uppuluri P, Tristan AR, et al. A simple and reproducible 96-well plate-based method for the formation of fungal biofilms and its application to antifungal susceptibility testing. Nature Protocols. 2008;3(9):1494. doi: 10.1038/nprot.2008.141

12. Panacek A, Kolar M, Vecerova R, et al. Antifungal activity of silver nanoparticles against Candida spp. Biomaterials. 2009;30(31):6333-6340. doi: 10.1016/j. biomaterials.2009.07.065

13. Fidel PL, Vazquez JA, Sobel JD. Candida glabrata: review of epidemiology, pathogenesis, and clinical disease with comparison to C. albicans. Clin Microbiol Rev. 1999;12(1):80-96. doi: 10.1128/CMR.12.1.80

14. Cornistein W, Mora A, Orellana N, Capparelli FJ, del Castillo M. Candida: epidemiology and risk factors for non-albicans species. Enferm Infecc Microbiol Clin. 2012;31(6):380-384. doi: 10.1016/j.eimc.2012.09.011 